\title{
NETWORK ADDRESS TRANSLATION PENGHUBUNG IP PUBLIC DAN IP PRIVATE PADA JARINGAN KOMPUTER
}

\author{
Asiah Azahro ${ }^{(1)}$, Desy Wulandari ${ }^{(2)}$ \\ Program Studi Teknik Informatika ${ }^{(1,2)}$ \\ Fakultas Ilmu Komputer, Universitas Lancang Kuning ${ }^{(1,2)}$ \\ Jalan Yos Sudarso No.KM. 8, Umban Sari, Kec. Rumbai, Rumbai,Pekanbaru, Riau 28266 \\ Email: ${ }^{(1)}$ asiahazahro16@gmail.com, ${ }^{(2)}$ desywulandari2288@gmail.com
}

\begin{abstract}
ABSTRAK
Sejalan dengan perkembangan teknologi informasi, peralatan-peralatan pendukung jaringan komputer masih sangat diperlukan. Peralatan tersebut pun kini menjadi komponen penting dalam pembangunan jaringan komputer. Router adalah salah satu komponen pada jaringan komputer yang mampu melewatkan data melalui sebuah jaringan atau Internet menuju sasarannya, melalui sebuah proses yang dikenal sebagal routing. Router berfungsi sebagal penghubung antar dua atau lebih jaringan untuk meneruskan data dan satu jaringan kejaringan lainnya. Router sendiri berharga tinggi dan masih sulit dijangkau oleh kalangan masyarakat kita. Router Mikrotik adalah solusi murah bagi mereka yang membutuhkan sebuah router handal dengan hanya bermodalkan standalone computer dengan sistem operasi Mikrotik. OIeh sebab itu, penulis merasa perlu membahas tentang "Kajian Network Address Translation Penghubung Ip Public Dan Ip Private". Dalam pembahasan penulis menitik beratkan pada membuat sebuah Topologi Local Network dengan IP Private untuk terhubung dengan IP Public”.
\end{abstract}

Kata kunci: Jaringan Komputer, Topologi, Router, NAT

\section{ABSTRACT}

In line with the development of information technology, computer network support equipment is still needed. The equipment has now become an important component in the development of computer networks. Router is one component in a computer network that is able to pass data through the network or the Internet to its target, through a process known as routing. Routers work as links between two or more networks to improve data and one other network. The router itself is high-priced and still difficult to reach by our society. Mikrotik Router is an inexpensive solution for those who need a reliable router with only a standalone computer with the Mikrotik operating system. For this reason, the author needs to discuss "Study of Network Addresses for Translation of Public and Private IP Connectors". In the discussion, the author focuses on creating a Local Network Topology with Private IP to connect with Public IP".

Keywords: Computer Networks, Topology, Routers, NAT

\section{PENDAHULUAN}

\subsection{Latar Belakang}

Routing merupakan proses dimana sesuatu dibawa dari satu lokasi ke lokasi lainnya. Contoh riil sesuatu yang membutuhkan perutean adalah surat, panggilan telepon, perjalanan kereta api, dan lain sebagainya. Pada suatu jaringan router adalah perangkat yang digunakan untuk merutekan trafik jaringan. Untuk dapat melakukan perutean, suatu router, atau entitas apapun yang membangun routing. Pada suatu sistem jaringan komputer, router mempelajari informasi routing dari sumber-sumber routing-nya yang terletak di dalam tabel routing (routing table). Router akan berpedoman 
pada tabel ini untuk menyatakan port mana yang digunakan mem-forward paket-paket yang ditujukan kepadanya. . Jika jaringan tujuan terhubung langsung dengan router, maka router sudah mengetahui port mana yang digunakan untuk mem-forward paket. · Jika jaringan tujuan tidak terhubung langsung dengan router, maka router harus mempelajari rute terbaik untuk mem-forward paket ke tujuan.

\subsection{Tujuan}

Tujuan dilakukan penulisan ini adalah :

- Mengetahui Alamat tujuan

- Mengenali sumber-sumber informasi perutean

- Menemukan rute-rute

- Memelihara dan memverifikasi informasi routing

\section{TINJAUAN PUSTAKA}

\subsection{Tinjauan Umum}

\section{Internet Protocol}

Internet Protocol (IP) adalah protokol yang mengatur routing dari pentransmisian melewati jaringan antara pengirim dan penerima. IP dapat dikatakan sebagai perantara komunikasi antar-komputer dengan menggunakan IP address sebagai suatu identitas dari jaringan atau komputer. IP address terdiri dari 32 bit dan terbagi menjadi dua bagian, yaitu network ID dan host ID (Rachman dan Yugianto, 2008).

IP versi 4 (IPv4) sudah ada sejak awal 1980-an dan versi ini banyak digunakan sampai saat ini. IP adalah salah satu protokol utama dalam TCP/IP. Dalam model OSI, protokol bekerja pada lapisan network dan fungsi utama dari protokol adalah mengidentifikasi host berdasarkan alamat logis mereka untuk rute data antara mereka melalui jaringan. Alamat logis dari sebuah host dalam jaringan adalah alamat IP dan IPv4 skema pengalamatan yang telah digunakan untuk sementara waktu sekarang dalam mengidentifikasi host dalam jaringan, sistem ini didasarkan pada 32-bit alamat logis (Babatunde dan AlDebagy, 2014).

Beberapa aturan dasar dalam menentukan network ID dan host ID yang dapat digunakan ketika akan membangun sebuah jaringan LAN, yaitu:

a) Network ID 127.0.0.1 tidak dapat digunakan, karena merupakan default yang digunakan untuk keperluan menunjuk dirinya sendiri (loop-back);

b) host ID tidak boleh di-set 1 (ex. 126.255.255.255), karena akan diartikan sebagai alamat broadcast (ID broadcast merupakan alamat yang mewakili seluruh anggota pada jaringan);

c) network ID dan host ID tidak boleh sama dengan 0 (ex. 0.0.0.0), karena IP address dengan

host ID 0 diartikan sebagai alamat network (alamat yang digunakan untuk menunjuk suatu jaringan,

dan tidak menunjuk suatu host); d) host ID harus unik dalam suatu network, dan dalam suatu

network tidak boleh ada dua host dengan host ID yang sama.[1]

\section{Network Address Translation}

Network Address Translation (NAT) adalah suatu metode untuk menghubungkan lebih dari satu komputer ke jaringan internet dengan menggunakan satu alamat IP public (Grang and Gupta, 2013). Metode NAT banyak digunakan di seluruh dunia termasuk di Indonesia. Pada dasarnya semua jenis NAT beroperasi dengan cara client - server. Dalam hal ini, klien di zona internal yang memulai permintaan untuk memperoleh sumber daya dari server di zona internet publik (Masoud, 2013). Di sini semua klien akan mendapatkan alamat IP lokal yang diberikan oleh komputer server. Dengan mekanisme NAT terbatasnya IP publik tidak menjadi masalah.

Salah satu syarat untuk menghubungkan komputer ke jaringan internet adalah dengan menggunakan IP publik. Melalui NAT memungkinkan 
beberapa node untuk berbagi satu atau lebih alamat IP publik. Gateway NAT berada pada batas jaringan lokal dan publik dan memodifikasi alamat IP lokal dan port dari paket yang diperuntukkan untuk jaringan publik. Paket IP yang dibundel dengan IPSec, seperti AH dan ESP secara intrinsik dimaksudkan untuk melindungi integritas dari paket IP (termasuk sumber dan tujuan alamat) dari perubahan atau gangguan karena peran.[1]

IP Address digunakan sebagai alamat dalam hubungan antar host di internet sehingga IP Address menjadi sebuah sistem komunikasi yang universal karena merupakan metode pengalamatan yang telah diterima di seluruh dunia. Dengan menentukan IP Address berarti kita telah memberikan identitas yang universal bagi setiap komputer. Jika suatu komputer memiliki lebih dari satu interface (misalkan menggunakan dua (ethernet) maka kita harus memberi dua IP Address untuk komputer tersebut masing-masing untuk setiap interfacenya.[2]

\subsection{Landasan Teori Jaringan Komputer}

Penggabungan teknologi komputer dan komunikasi sangat berpengaruh terhadap bentuk organisasi sistem komputer. Suatu konsep pusat komputer adalah merupakan konsep yang sudah ketinggalan jaman. Model komputer tunggal yang melayani seluruh tugas-tugas komputasi telah diganti dengan sekumpulan komputer berjumlah banyak yang terpisah-pisah tetapi saling berhubungan dalam melaksanakan tugasnya, sistem tersebut yang disebut dengan jaringan komputer (computer network). Selanjutnya istilah jaringan komputer adalah mengartikan himpunan interkoneksi (interconnected) sejumlah komputer autonomous.[3]

Suatu konsep pusat komputer adalah merupakan konsep yang sudah ketinggalan jaman. Model komputer tunggal yang melayani seluruh tugas-tugas komputasi telah diganti dengan sekumpulan computer berjumlah banyak yang terpisah-pisah tetapi saling berhubungan dalam melaksanakan tugasnya, sistem tersebut yang disebut dengan jaringan komputer (computer network).[3]

Tujuan dari jaringan komputer adalah agar dapat mencapai tujuannya, setiap bagian dari jaringan komputer dapat meminta dan memberikan layanan (service). Pihak yang meminta/menerima layanan disebut klien (client) dan yang memberikan/mengirim layanan disebut peladen (server). Desain ini disebut dengan sistem client-server, dan digunakan pada hampir seluruh aplikasi jaringan komputer.

Dalam tahap ini yang dilakukan adalah merancang desain topologi jaringan komputer, baik topologi fisik maupun topologi logis sesuai dengan ketersediaan teknologi yang ada. Sistem jaringan komputer merupakan sistem yang saling terkait, yang menyalurkan informasi atau data ke berbagai entitas yang terhubung. Apabila aliran ini tersendat atau terganggu, maka sistem akan terhenti sehingga akan menyebabkan koneksi antar entitas menjadi terhambat bahkan terputus. Untuk mengatasi hal tersebut, dibutuhkan perancangan desain jaringan komputer yang akan dibangun. Paradigma sistem jaringan komputer didasarkan pada realitas bahwa suatu jaringan komputer merupakan suatu sistem yang terdiri dari teknologi, perangkat keras, perangkat lunak, sumber daya manusia dan lingkungan.[4]

Jaringan komputer merupakan suatu sistem jaringan, dimana seluruh komputer saling berbagi data dan resources satu sama lain sehingga tercapai efisiensi dalam pemanfaatan teknologi informasi dan komunikasi. Sistem yang terdiri atas komputer, software dan perangkatperangkat jaringan lainya yang bekerja bersama-sama untuk mencapai suatu tujuan yang sama.[5] 


\section{Kriteria Jaringan}

Terdapat tiga kriteria paling penting dalam jaringan komputer yaitu Performance, Reliability, dan Security.[3]

a. Performance

Ukuran dari performance (kinerja) bisa bermacam-macam, termasuk di dalamnya adalah waktu transit (transit time) dan waktu respon (response time). Transit time adalah banyaknya waktu yang dibutuhkan data untuk melakukan "perjalanan" dari satu device (misal, komputer) ke komputer lainnya. Sedangkan response time adalah selisih waktu antara permintaan dengan respon terhadap permintaan.

b. Reliability

Dalam rangka menjamin akurasi pengiriman data, reliabilitas jaringan dapat dilihat melalui seberapa seringnya kegagalan pengiriman data (frequency failure) yang terjadi, waktu yang dibutuhkan untuk proses recover setelah terjadinya kegagalan (recovery time after a failure), dan antisipasi jaringan terhadap kejadian yang diluar sistem (catastrophe).

\section{c. Security}

Keamanan jaringan (security network) menjadi hal yang sangat penting manakala dihadap pada permasalahan akses pengguna terhadap sumberdaya jaringan (unauthorized access) dan serangan virus.

\section{Internetworking}

Seni dan ilmu pengetahuan dari menghubungkan antara LAN (Local Area Network) satu dengan LAN yang lainnya untuk menciptakan jaringan WAN (Wide Area Network) satu dengan WAN yang lainnya, sehingga terbentuk suatu jaringan yang lebih besar disebut juga internetworking.

\section{Network Operations Center (NOC)}

NOC Adalah tempat administrator mengawasi, memantau dan memelihara jaringan telekomunikasi. Sebuah perusahaan besar dengan jaringan serta penyedia layanan jaringan yang besar biasanya memiliki pusat jaringan operasi, sebuah ruangan yang berisi visualisasi dari jaringan atau jaringan yang sedang dipantau, workstation di mana status rinci jaringan dapat dilihat, dan perangkat lunak yang diperlukan untuk mengelola jaringan. Jaringan pusat operasi adalah titik fokus untuk mengatasi masalah jaringan, distribusi perangkat lunak dan update, router dan manajemen nama domain, memantau kinerja, dan koordinasi dengan jaringan afiliasi.

\section{Transmission \\ Control \\ Protocol/Internet Protocol (TCP/IP)}

TCP/IP termasuk dalam deretan protokol komunikasi yang digunakan untuk menghubungkan host - host pada jaringan internet. TCP/IP menggunakan banyak protokol di dalamnya, adapun protokol utamanya adalah TCP dan IP. Network Operations Center.

Dilihat dari penomorannya, port UDP dan TCP dibagi menjadi tiga jenis, yakni sebagai berikut:

a.) Well-known Port: yang pada awalnya berkisar antara 0 hingga 255 tapi kemudian diperlebar untuk mendukung antara 0 hingga 1023. Port number yang termasuk ke dalam well-known port, selalu merepresentasikan layanan jaringan yang sama, dan ditetapkan oleh Internet Assigned Number Authority (IANA).

b.) Registered Port: Port-port yang digunakan oleh vendor-vendor komputer atau jaringan yang berbeda untuk mendukung aplikasi dan sistem operasi yang mereka buat.

c.) Dynamically Assigned Port: merupakan port-port yang ditetapkan oleh sistem operasi atau aplikasi yang digunakan untuk melayani request dari pengguna sesuai dengan kebutuhan. DynamicallyAssigned Port berkisar dari 
1024 hingga 65536 dan dapat digunakan atau dilepaskan sesuai kebutuhan.[6]

Network Manajemen Salah satu pekerjaan yang mungkin paling sulit untuk dilakukan adalah mengatur / memanage banyak peralatan jaringan, seperti, router,gateway, server dll. Untuk keperluan tersebut, di kembangkan Simple Network Management Protocol (SNMP) yang merupakan bagian dari keluarga protokol Internet yang di definisikan oleh Internet Engineering Task Force (IETF). [7]

SNMP adalah protokol untuk melakukan network manajemen. SNMP digunakan untuk mengumpulkan informasi, dan mengkonfigurasi, peralatan jaringan, seperti, server, printer, hub, switch, dan router di jaringan berbasis Internet Protocol (IP). SNMP dapat mengumpulkan informasi seperti kondisi CPU, temperatur chasis, dan hampir tidak ada batas akan apa yang dapat dikonfigurasi oleh SNMP. Protokol SNMP di rancang untuk memberikan metode "sederhana" untuk memanage jaringan TCP/IP secara terpusat.memanagen peralatan dari komputer pusat, protokol SNMP akan memfasilitasi transfer data dari sisi client sampai sisi server dimana data secara terpusat di catat, di lihat dan di analisa. SNMP tersediri dari sekumpulan standard manajemen jaringan, termasuk di dalamnya definisi aplikasi di lapisan aplikasi, schema database dan sekumpulan objek data.Tujuan utama dari protokol SNMP hanya pada satu tujuan saja, dan masih digunakan hingga hari ini, yaitu, melakukan remote manajemen dari peralatan.SNMP banyak digunakan untuk memanage peralatan di jaringan komputer.

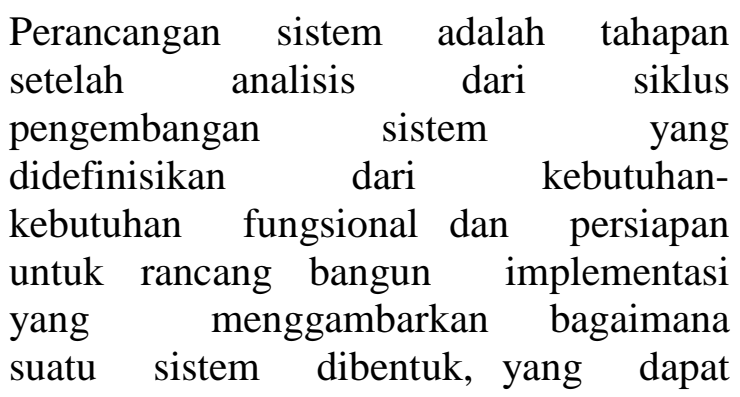

berupa penggambaran, perancangan, dan pembuatan sketsa atau pengaturan dari beberapa elemen yang terpisah kedalam satu kesatuan yang utuh dan berfungsi juga menyangkut konfigurasi dari komponen-komponen perangkat keras dan perangkat lunak.[8]

Metode pengembangan terstruktur dengan pendekatan siklus hidup pengembangan sistem (System Development Life Cycle atau SDLC). Terdiri dari beberapa fase antara lain sebagai berikut :

a. Perencanaan (Planning)

Pada tahap ini lebih fokus pada penafsiran kebutuhan dan diagnosa masalah dengan mendefinisikan sasaran dan tujuan dari sistem yang akan dibangun.

b. Analisa Sistem (System Analysis)

Pada fase ini dilakukan analisa terhadap sistem yang ada dengan metode yang digunakan yaitu metode wawancara dengan pihak-pihak yang terkait dan melakukan pengamatan terhadap kondisi pemda yang menjadi ruang lingkup penelitian. Pada fase ini meliputi: menentukan obyek, mempelajari organisasi, menganalisis kebutuhan output, menganalisis kebutuhan input, evaluasi efektifitas sistem.

c. Perancangan Sistem (System
design)
Dalam merancang sistem ini berdasar pada kebutuhan dan masalah yang dihadapi pada obyek penelitian. Pada fase ini meliputi perancangan basis data, perancangan antar muka pengguna, kebutuhan perangkat keras, perancangan jaringan, kebutuhan perangkat lunak.

d. Implementasi Sistem (System
Implementation)
Setelah melalui tahapan requirement, analysis dan design, maka seluruh sistem siap untuk diimplementasikan. Dalam tahapan implementasi ada beberapa tugas yang dijalankan diantaran mengimplementasikan design dalam 
komponen-komponen, souce code, script, executable sebagainya.

e. Operasi dan pemeliharaan sistem (System operation and maintenance). Pada tahap ini dilakukan pelatihan terhadap pengguna dan evaluasi terhadap sistem yang berjalan,apabila ada kekurangan maupun kesalahan diadakan perbaikan dan perawatan.[9]

Berikut merupakan beberapa tahapan pengembangan Model Sekuensial Linier / Waterfall Development Model :

a. Pencangan sistem

Tahap pertama mulai membangun elemen sistem dan memilih bagian mana saja yang akan digunakan sebagai bahan pengembangan perangkat lunak, dengan memperhatikan hubungan dengan hardware, Database dan User.

b. Analisis sistem

Tahap ini melakukan analisa dan mengumpulkan kebutuhan-kebutuhan sistem seperti fungsi yang diperlukan untuk performansi/ kerja dan antarmuka. Hasil anlaisa dan kumpulan data tersebut didokumentasikan.

c. Desain sistem

Tahap ini proses desain, dilakukan dengan menerjemahkan syarat kebutuhan suatu perancangan perangkat lunak yang bisa diperkirakan sebelum dibuatnya proses pengkodean (coding).

d. Pengkodean program

Tahap pengkodean ini adalah proses penerjemahan perancangan desain ke dalam bentuk yang bisa dimengerti oleh mesin menggunakan bahasa pemrograman.

e. Implementasi sistem

Tahapan akhir desain program dibangun diterjemahkan ke dalam kodekode yang menggunakan bahasa pemrograman dan langsung diuji secara unit.

f. Uji coba program

Proses pengujian logika internal dan pengujian eksternal fungsional terhadap program perangkat lunak, untuk memeriksa segala kemungkinan yang dapat terjadi seperti kesalahan dan juga memeriksa apakah hasil pengembangannya sesuai dengan yang dirancang.[10]

\section{HASIL DAN PEMBAHASAN}

Ada beberapa pembagian dari jenis jenis jaringan yaitu :

(1) LAN (Local Area Network)

LAN (Local Area Network) merupakan suatu jaringan komputer yang masih berada di dalam gedung atau ruangan. Dalam membuat jaringan LAN, minimal harus menyediakan dua buah komputer yang masing-masing memiliki kartu jaringan Lan Card. LAN digunakan di rumah, perkantoran, industri, akademik, rumah sakit, dan lain sebagainya.

(2) MAN (Metropolitan

Area Network)

Metropolitan Area Network (MAN) merupakan pengemmbangan dari LAN. Jaringan ini terdiri dari beberapa jaringan LAN yang saling berhubungan. Jangkauan dari MAN ini antar 10 hingga $50 \mathrm{~km}$, MAN ini merupakan jaringan yang tepat untuk membangun jaringan antar kantor kantor dalam satu kota antara pabrik atau instansi dan kantor pusat yang berada dalam jangkauannya. MAN mampu menunjang data dan suara, bahkan dapat digunakan untuk aplikasi TV kabel.

(3) WAN (Wide Area Network)

WAN (Wide Area Network) merupakan jaringan komputer yang mencakup area yang besar sebagai contoh yaitu jaringan computer antar wilayah, kota atau bahkan negara, atau dapat didefinisikan juga sebagai jaringan komputer yang membutuhkan router dan saluran komunikasi publik. WAN (Wide Area Network) merupakan bentuk jaringan yang terdiri dari LAN dan MAN.[11]

Berdasarkan media transmisi data dibedakan menjadi :

- Jaringan Berkabel (Wired Network) Pada jaringan ini, untuk menghubungkan satu komputer dengan komputer lain 
diperlukan penghubung berupa kabel jaringan. Kabel jaringan berfungsi dalam mengirim informasi dalam bentuk sinyal listrik antar komputer jaringan.

- Jaringan Nirkabel (Wireless Network) Merupakan jaringan dengan medium berupa gelombang elektromagnetik. Pada jaringan ini tidak diperlukan kabel untuk menghubungkan antar komputer karena menggunakan gelombang elektromagnetik yang akan mengirimkan sinyal informasi antar komputer jaringan.

Berdasarkan peranan Komputer dalam Proses Data :

\section{- Jaringan Client-Server}

Pada jaringan ini terdapat 1 atau beberapa komputer server dan komputer client. Komputer yang akan menjadi komputer server maupun menjadi komputer client dan diubahubah melalui software jaringan pada protokolnya. Komputer client sebagai perantara untuk dapat mengakses data pada komputer server sedangkan komputer server menyediakan informasi yang diperlukan oleh komputer client.

- Jaringan Peer-to-peer

Pada jaringan ini tidak ada komputer client maupun komputer server karena semua komputer dapat melakukan pengiriman maupun penerimaan informasi sehingga semua komputer berfungsi sebagai client sekaligus sebagai server.

\section{Router}

Router adalah suatu perangkat keras pada jaringan komputer yang berfungsi untuk menghubungkan beberapa jaringan, baik itu jaringan yang sama maupun jaringan yang berbeda dari sisi teknologinya.[12]

Ada juga yang menjelaskan bahwa pengertian router adalah suatu hardware jaringan komputer yang berfungsi untuk mengirimkan paket data melalui jaringan atau internet dari satu perangkat komputer ke perangkat lainnya, dimana proses tersebut disebut dengan routing. Setiap router mempunyai fasilitas $D H C P$ (Dynamic Host Configuration Procotol) yang dapat disetting sedemikian rupa sehinga dapat membagi IP address. Selain itu, pada router juga terdapat NAT (Network Address Translator) yaitu fasilitas yang memungkinkan suatu alamat IP atau koneksi internet dapat di-sharing ke alamat IP lain.

Sepintas router mirip dengan bridge, namun router lebih pintar dibandingkan bridge. Router bekerja menggunakan routingtable yang disimpan di memori untuk membuat keputusan tentang kemana paket akan kirimkan. Router dapat memutuskan rule terbaik yang akan ditempuh paket data. Router adalah jaringan yang dapat menghubungkan satu jaringan kejaringan lain. Sepintas router mirip dengan bridge, namun router lebih pintar dibandingkan bridge. Router bekerja menggunakan routingtable yang disimpan di memori untuk membuat keputusan tentang kemana paket akan kirimkan. Router dapat memutuskan rule terbaik yang akan ditempuh paket data.[13]

Router merupakan suatu alat atau program aplikasi yang berfungsi menentukan titik mana suatu paket data harus diteruskan ke jaringan yang lain. Router akan memilih jalan terdekat untuk melewatkan paket aplikasi data . Aplikasi-aplikasi yang berada pada router, jika telah terinstal pada sebuah komputer dinamakan PC router.

Router bekerja pada level network layer pada model jaringan OSI. Router memiliki kemampuan lebih baik daripada bridge. Router dapat digunakan untuk menghubungkan sejumlah LAN, sehingga trafik yang dibangkitkan oleh sebuah LAN akan terisolasikan dengan baik dari trafik LAN lain.[11]

Memiliki Fungsi : 
1. Meroutingkan paket-paket data dengan suatu segmen jaringan yang berbeda.

2. Menyimpan routing table untuk menentukan rute terbaik antara LAN ke WAN.

3. Perangkat di layer 3 OSI Layer.

4. Bisa berupa "box" atau sebuah OS yang menjalankan sebuah daemon routing

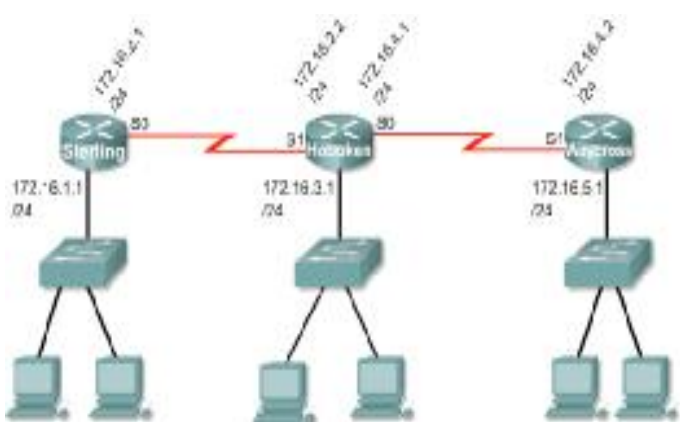

Gambar konfigurasi sederhana dengan 3 router

\section{Tipe Router}

\section{Router Statis}

Cara kerja Router statis dapat dibagi menjadi beberapa bagian yaitu :
a. Administrator jaringannya yang mengkonfigurasi router .
b. Router melakukan Router berdasarkan informasi dalam table Router

\section{Router Dinamis}

Router protocol adalah berbeda dengan routed protocol. Router protocol adalah komunikasi antara router-router. Router protocol mengijinkan router-router untuk sharing informasi tentang jaringan dan koneksi antar router. Router menggunakan informasi ini untuk membangun dan memperbaiki table Router nya.

Contoh Router Protokol:
a. Router Information Protocol (RIP)
b. Interior Gateway Router Protocol (IGRP)

\section{c. Enhanced Interior Gateway Router Protocol (EIGRP) \\ d. Open Shortest Path First (OSPF).[11]}

Setiap kali sesorang berselancar di internet menggunakan komputer, sebetulnya komputer tersebut haruslah memiliki alamat IP yang telah terdaftar melalui ISP. Alamat IP yang diperuntukkan oleh publik (pengguna komputer) ini cukup terbatas, dan semakin hari jumlahnya pun semakin menipis.

Untuk itulah kemudian hadir sistem NAT untuk mengatasi masalah jumlah alamat IP yang semakin menipis ini. Tak hanya itu, NAT pun memiliki fungsi dan keunggulan lain yang membuatnya diperlukan banyak orang.

Penggunaan utama dari Network Address Translation (NAT) adalah untuk membatasi jumlah alamat IP publik suatu organisasi atau perusahaan menggunakan IP publik baik untuk tujuan ekonomi maupun tujuan keamanan. NAT merupakan salah satu protocol dalam suatu sistem jaringan, NAT memungkinkan suatu jaringan dengan IP yang bersifat private atau private IP yang sifatnya belum teregistrasi di jaringan internet untuk mengakses jalur internet.[14]

\section{Network Address Translation (NAT)} adalah suatu metode untuk menghubungkan lebih dari satu komputer ke jaringan internet dengan menggunakan satu alamat IP, merupakan teknologi yang memungkinkan jaringan IP Private dapat membagi koneksi akses internet jaringan yang didisain untuk menyederhanakan IP address dan berperan juga untuk melindungi jaringan dan kemudahan serta fleksibilitas dalam administrasi jaringan. 


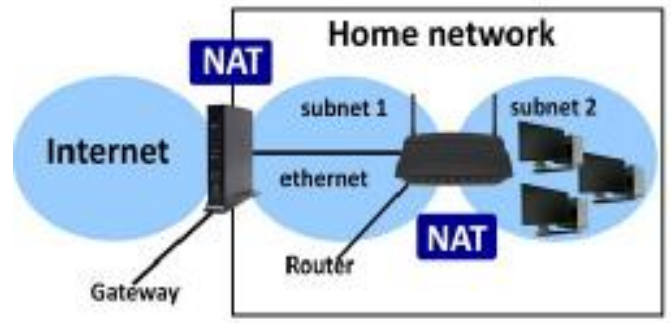

Network Address Translation (NAT) merupakan sebuah sistem untuk menggabungkan lebih dari satu komputer untuk dihubungkan ke dalam jaringan internet hanya dengan menggunakan sebuah alamat IP. Sehingga setiap komputer di dalam NAT ketika berselancar di internet akan terlihat memiliki alamat IP yang sama jika dilacak. Dengan kata lain, sebuah alamat IP pada jaringan lokal akan terlebih dahulu ditranslasikan oleh NAT untuk dapat mengakses IP publik di jaringan komputer. Sebelum proses translasi ini, maka pengguna tidak dapat terhubung ke internet.

Banyak yang berpendapat bahwa NAT sebetulnya mirip dengan proxy server, namun bedanya adalah jika proxy server menyediakan mekanisme caching, tak begitu halnya dengan NAT. Sehingga dengan penggunaan NAT, tidak ada batasan mengenai jumlah halaman web yang dapat diakses.

Cukup banyak pengguna NAT yang memanfaatkan sistem ini, bisa jadi dikarenakan ketersediaan alamat IP yang terbatas, membutuhkan keamanan lebih, atau ada pula yang menggunakan NAT karena dinilai lebih fleksibel dalam hal administrasi jaringan, sebab jaringan NAT didesain menyederhanakan alamat IP dan untuk melindunginya.

Misalkan di sebuah gedung terdapat beberapa komputer yang saling terhubung dalam suatu LAN. Untuk terkoneksi dengan internet maka kita harus mempunyai IP yang disebut IP public. IP public ini bisa kita dapatkan dengan menghubungi IP public ini bisa kita dapatkan dengan menghubungi Internet Network Information Center (InterNIC) yaitu suatu badan yang mengelola pemakaian alamat IP dan nama domain. Kemudian IP public ini dibagi menjadi beberapa alamat komputer pada LAN dan disebut IP private. IP public ditranslasikan menjadi IP private menggunakan mekanisme NAT. Gambar 1 menunjukkan penempatan PC Router sebagai NAT. Fungsi NAT dapat diilustrasikan pada gambar 1 berikut[15] :

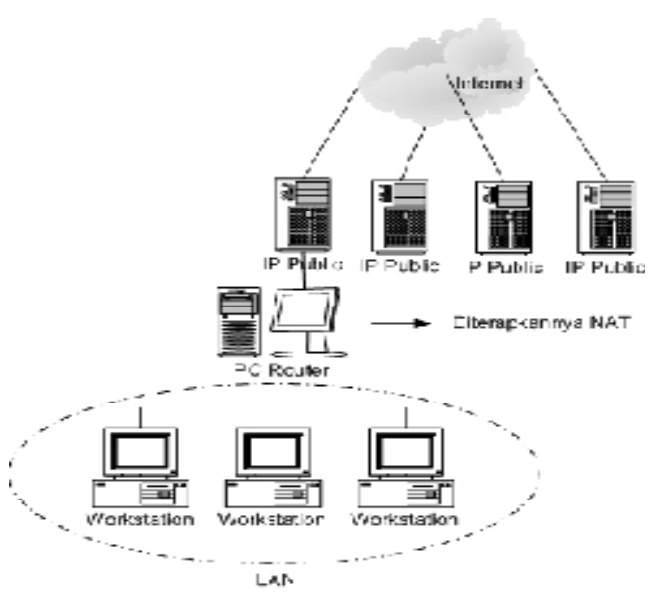

Gambar Penempatan PC Router sebagai NAT

\section{Jenis-Jenis NAT}

Secara singkat, ada empat jenis NAT yang perlu diketahui, yaitu NAT tipe statis, dinamis, overloading, dan overlapping. Perbedaan antara keempatnya akan dibahas dalam poin berikut :

\section{NAT Statis}

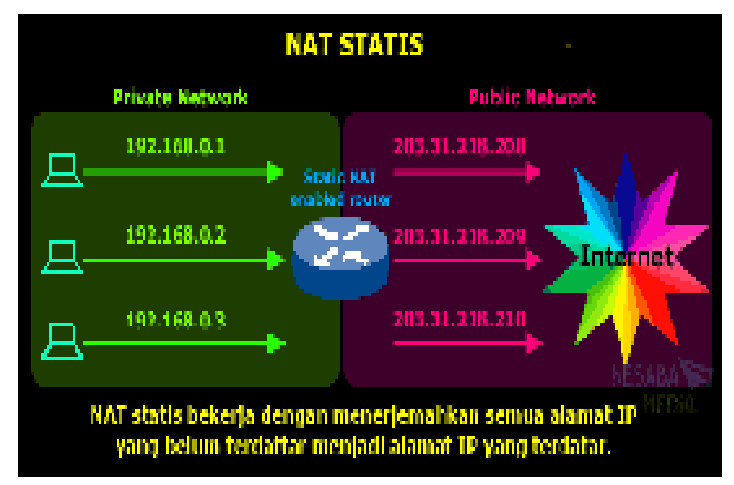


Bekerja dengan menerjemahkan semua alamat IP yang belum terdaftar menjadi alamat IP yang terdatar. NAT Statis banyak digunakan untuk komputer yang ingin dapat diakses dari luar. NAT statis ini sebetulnya bisa dibilang pemborosan terhadap alamat IP yang didaftarkan, sebab setiap satu komputer dipetakan untuk satu alamat IP terdaftar, sehingga jika ada banyak komputer yang didaftarkan, tentu semakin terbatas pula alamat IP yang masih tersedia. Kekurangan lain dari NAT Statis adalah kurang aman dibandingkan NAT dinamik, sebab setiap komputer memiliki alamat IP tersendiri, dan akhirnya risiko penyusup masuk langsung ke dalam jaringan private lebih besar.

\section{NAT Dinamis}

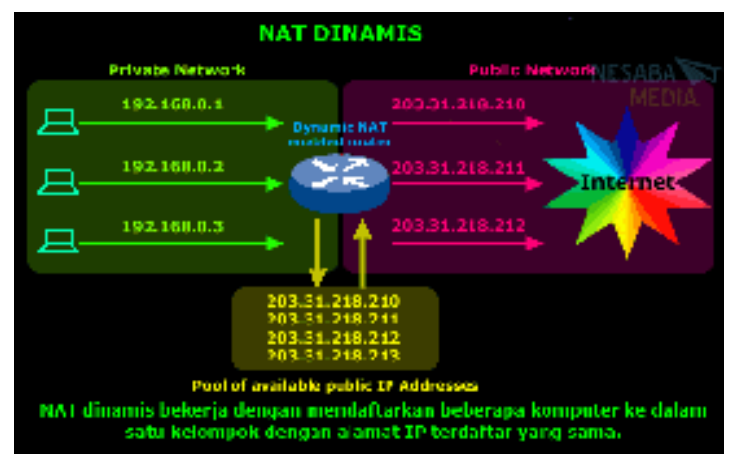

Berbeda dengan NAT Statis, NAT Dinamis bekerja dengan mendaftarkan beberapa komputer ke dalam satu kelompok dengan alamat IP terdaftar yang sama. Sehingga nantinya ada beberapa komputer yang memiliki kesamaan alamat IP terdaftar. Keuntungan menggunakan NAT dinamis ini tentu lebih amannya penelusuran di internet.

\section{Overloading NAT}

Memungkinkan lebih dari satu klien terhubung menuju satu IP publik, namun pada port yang berbeda. Sehingga saat NAT menerima permintaan dari klien untuk dihubungkan kepada server, NAT kemudian akan menentukan nomor IP dan port untuk klien tersebut. Keuntungannya adalah walaupun sebuah nomor IP telah digunakan, namun masih bisa dipakai untuk klien lain sebab berada dalam port yang berbeda.

\section{Overlapping NAT}

Bentuk NAT yang melakukan penerjemahan dua arah, terutama jika terdapat nomor yang sama antara alamat IP publik dan lokal. Agar tidak terjadi konflik, maka NAT mengubah nomor IP publik menjadi nomor yang tidak terdapat dalam jaringan lokal.

\section{Fungsi NAT}

Ada beberapa fungsi NAT, yaitu :

1. Melakukan penghematan terhadap IP legal yang disediakan oleh Internet Service Provider (ISP).

2. Meminimalisir adanya duplikasi alamat IP dalam jaringan.

3. Ketika terjadi perubahan jaringan, menghindari proses pengalamatan kembali.

4. Menambah fleksibilitas untuk terhubung dengan jaringan internet.

5. Melakukan peningkatan terhadap keamanan sebuah jaringan.

6. Dibandingkan dengan aplikasi alternatif seperti proxy, penggunaan NAT memberikan fleksibilitas dan performa yang lebih baik.

Walaupun begitu, dibalik semua fungsi dan kelebihannya, sebetulnya ada juga beberapa kekurangan yang mesti dirasakan pengguna NAT, seperti misalnya mengalami Delay Switching ketika proses translasi, kehilangan kemampuan melacak IP end to end, dan juga ada beberapa aplikasi yang menolak bekerja saat menggunakan NAT. 


\subsection{Cara Kerja NAT}

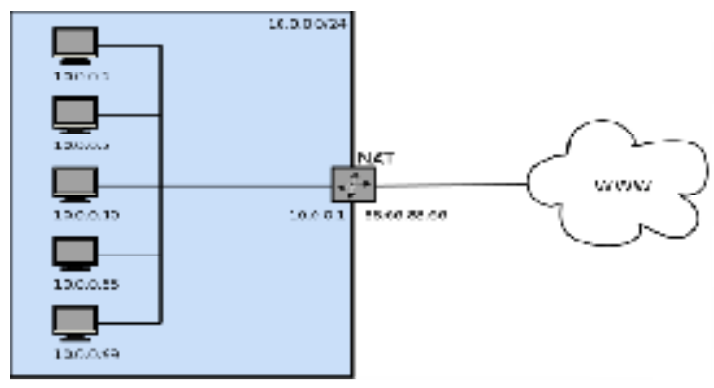

Cara Kerja NAT

Saat menggunakan NAT, seorang klien dapat terhubung dengan internet melalui proses-proses berikut :

1. Pertama-tama, NAT menerima permintaan dari klien berupa paket data yang ditujukan untuk sebuah server remote di internet.

2. NAT kemudian mencatat alamat IP klien, lalu menyimpannya ke dalam tabel translasi alamat. Selanjutnya, alamat IP komputer klien tersebut diubah oleh NAT menjadi nomor IP NAT, lalu NAT lah yang akan melakukan permintaan kepada server.

3. Server kemudian merespon permintaan tersebut. Dari sudut pandang server, yang terlihat adalah alamat IP NAT, bukan alamat IP klien yang meminta data bersangkutan.

4. NAT menerima respon dari server, lalu melanjutkannya dengan mengirimkan ke alamat IP klien yang bersangkutan.

5. Keempat tahapan tersebut terjadi berulang-ulang, sehingga walaupun klien komputer tidak memiliki alamat IP publik, namun tetap dapat mengakses internet.

\section{PENUTUP}

\subsection{Kesimpulan}

NAT dapat digunakan jika jumlah IP yang dimiliki sedikit sedangkan komputer yang akan disambungkan ke internet cukup banyak. Penggunaan mekanisme NAT dalam jaringan dapat menghemat biaya karena efisien dalam pemakaian IP public dan penerapan NAT dalam jaringan dapat meningkatkan efisiensi manajemen LAN dalam internetworking.

\section{DAFTAR PUSTAKA}

[1] T. Tutang, "Implementasi Network Address Translation (Nat) Menggunakan Kerio Control Versi 7.4.1 Di Pusat Penelitian Bioteknologi - Lipi," Baca J. Dokumentasi Dan Inf., vol. 36, no. 1, p. 97, 2016.

[2] T. D. Purwanto et al., "Perancangan Jaringan Vpn Router Dengan," pp. 6974, 2014.

[3] W. Sugeng and S. Mery, "Analisis Jaringan Komputer Dinas Komunikasi Dan Informatika," 2013, vol. 3, no. 1, p. 8, 2012.

[4] L. Lukman, A. M. Saputro, A. S. Wicaksono, F. H. T. Hartomo, and M. N. Jatun, "Manajemen Bandwidth Menggunakan Metode Hierarchical Token Bucket (HTB) di Farid.net," Creat. Inf. Technol. J., vol. 5, no. 3, p. 209, 2019.

[5] F. Ardianto, "Penggunaan mikrotik router sebagai jaringan server," no. 1 , pp. 26-31, 2011.

[6] A. Widodo, "Implementasi Monitoring Jaringan Komputer Menggunakan Dude," Teknol. Inf., vol. 11, pp. 1-10, 2015.

[7] F. A. Syam, "PUSAT TEKNOLOGI INFORMASI DAN PANGKALAN DATA UIN SUSKA DESIGN OF STRATEGIC PLANNING INFORMATION TECHNOLOGY IN INFORMATION TECHNOLOGY CENTER AND DATA CENTER OF UIN SUSKA RIAU Febrizal Alfarasy Syam PENDAHULUAN Untuk mendukung visi UIN Suska Riau yaitu menj," vol. 1, no. 2, pp. 183-197, 
2018.

[8] E. S. Pane and M. Sadar, "Sistem Informasi Penjualan Boneka Berbasis Web ( Studi Kasus: Asrama Boneka Unilak )," J. Teknol. Inf. Komun. Digit. Zo., vol. 6, pp. 25-33, 2015.

[9] B. Febriadi and N. Nasution, "Efisiensi sistem informasi berbasis online dalam pengumpulan rpkps mata kuliah Untuk pengembangan kompetensi program studi," Digit. Zo. J. Teknol. Inf. dan Komun., vol. 8, no. 1, pp. 33-42, 2017.

[10] N. Siregar, Zamzami, and Guntoro, "Sistem Informasi Catering di Ratu Catering Berbasis Web," vol. 1, no. 2, pp. 104-114, 2019.

[11] P. Soepomo, "Media Pembelajaran Komunikasi Data Dan Jaringan," vol. 2, pp. 10-20, 2014.

[12] W. Syafitri, "Perencanaan Strategi Sistem Informasi/Teknologi Informasi Universitas Lancang Kuning Menggunakan Metode Ward And Peppard," Teknol. Inf. Komun. Digit. Zo., vol. 7, no. 1, pp. 31-43, 2015.

[13] A. Putri, "Analisa Kinerja Koneksi Jaringan Komputer Pada SMK Teknologi Bistek Palembang," Anal. Kinerja Koneksi Jar. Komput. pada SMK Teknol. Bistek Palembang, no. 12, 2017.

[14] J. Natali and T. M. Diansyah, "Implementasi Static Nat Terhadap Jaringan Vlan Menggunakan Ip Dynamic Host Configuration Protocol (Dhcp)," J. Ilm. Inform., vol. 1, no. 1, pp. 51-58, 2016.

[15] Wahyuni, M. Nasrun, and Irzaman, "Analisa Penggunaan Mekanisme Network Address Translation (NAT) untuk Menghemat Internet Protocol (IP) Address," pp. 1-8, 2017. 